\title{
Investment Opportunity in Online Survey Industry under COVID-19
}

\author{
Yinuo Cheng ${ }^{1}$ \\ ${ }^{1}$ Shandong Experimental High School, Shandong, China
}

\begin{abstract}
The COVID-19 outbreak left the world an island shrouded in repression, causing great losses to the world economy and blowing numerous investors in the financial market. However, at the same time, emerging online industries also bring them new investment opportunities. This article would analyze the operation condition and forecast the growth potential of three enterprises, Zoom Video Inc., Shanghai Yaoji Technology Co., Ltd, and 51Talk, which specialize in Online Entertainment, Online Education, and Office Online. Through analyzing operating profit growth rate and net profit growth rate of Zoom Video Inc., classifying Shanghai Yaoji Technology Co., Ltd in terms of ROIC and increase rate of main business revenue, and predicting stock returns of 51 talk using Baidu Index, short-term and long-term investment strategies can be provided. With the above evidence, it is proposed that Shanghai Yaoji Technology Co., Ltd is worthy to invest in the short run, while Zoom Video Inc. and 51Talk have larger profitability in the long term. Besides, the future of those online industries is predicted.
\end{abstract}

\section{INTRODUCTION}

For several times at the meeting of the World Health Organization (WHO), the director-general Dr. Tedros Adhanom Ghebreyesus asserted that COVID-19 is not just a public health crisis, but it will affect all walks of life[1]. The disease indeed brought irreversible social and economic chaos to mankind. Taking one of the worst hit areas, America, as an example, with nearly 33.3 million people out of work[2], America is in the face of the worst unemployment crisis since the Great Depression happened. Mass unemployment has led to a disconnection in the product supply chain. Large amounts of small and medium private enterprises and companies in traditional service industries are facing huge a financial crisis. The financial market made the most intuitive response to the economic crisis. The U.S. stock market had touched the circuit breaker mechanism four times in ten days. In fact, uncertain financial markets are eroding investors' confidence.

However, the unexpected boom in the online industry has brought new investment opportunities for investors[3]. This paper aims at analyzing the financial data and stock's value of the leading companies in three online industries: Online Entertainment, Online Education, and Office Online discussing those companies' performances and industries' growth potential and providing investors with short-term and long-term investment suggestions. It is hoped that this paper can raise chances for investors to get benefits from financial markets under the influence of COVID-19 and forecast the industries with great potential in the following years.

\section{OnLINe SerVice}

The global outbreak has forced thousands of people to stay at home. At this moment, online industries that rely on the Internet have become a key beneficiary of the popularity of domestic policies in many countries.

The office online sector has encountered its development opportunities. Thanks to its software's convenient, smooth and economical characteristics, ZOOM Video Inc. has become the leader of the world's main online video conferencing companies in just a few months. According to the data provided by Apptopia, as of March 22, Zoom's daily active users increased by $378 \%$ from the same period last year, and the number of monthly active users increased by $186 \%$ [4]. Compared with the data at the end of December last year, the number of DAU and MAU increased by approximately $340 \%$ and $160 \%$, respectively. At the same time, Zoom's stock also developed rapidly. Despite U.S. stocks hitting the circuit breaker four times in 10 days, Zoom Video Inc. shares fell only a slight by $10 \%$, before turning immediately upward. The nontraditional business growth and the strong stock suggest the Zoom Video Inc. may have strong growth prospects.

With more leisure time and limited entertainment options available during the coronavirus outbreak, the online entertainment industry has come to a head during the epidemic. The overall performance of the online game industry represented by Shanghai Yaoji Technology Co., Ltd is quite outstanding. Yaoji said that during the reporting period, the overall number of active users and the flow of the company's game business sector grew

1814423163@qq.com 
significantly. At the same time, the company's overseas game business sector also grew steadily. Yaoji forecast net profit attributable to shareholders in the first quarter of 2020 to be between 132 million yuan and 174 million yuan with a year-on-year growth rate of $150 \%$ to 230 percent[5]. With the outstanding performance, Shanghai Yaoji Technology Co. is worthy to be noticed.

In the case of complete isolation, online education has also grown. Third-party platforms or online MOOC companies, such as Coursera, Udacity, and Udemy, working with universities have facilitated thousands of students during the epidemic. 51Talk, an online English teaching enterprise, is a typical case. In the first quarter of 2020, 51 talk generated 487.1 million yuan (\$68.8 million) in revenue, achieving 52.2 percent increase year on year. The net profit was 50.8 million yuan, a year-on-year turn round. It is reported that 51Talk's cash revenue increased to 596.9 million yuan in the first quarter. Even compared with the fourth quarter of 2019 , the peak season for the whole year, it is a significant increase. At the same time, the growth in users is considerable. The number of active students in the first quarter was about 286,600 , increasing 11.4 percent from 257,200 in the previous quarter[6].

\section{ANALysis IN ThREe LeVEL}

This article will use three analytical methods to determine whether the office online sector, online entertainment sector, and online education sector have the short-term and long-term investment value. With the result, the author will provide investment advice for investors. In general, there are three models:

1) Using the operating profit growth rate and net profit growth rate does the combined analysis of corporate profitability and growth capabilities.

2) Combining ROIC and increase rate of main business revenue comprehensively judge whether the company has a long-term structural competitive advantage

3) Based on the established hypothesis related to the influence of investor attention on stock returns, the article will forecast growth potential of the company's stock in the long run.

\subsection{Opeprfgrrt and Netprfgnt Analysis}

Using this model, this article analyzes data from four quarterly financial statements of Zoom Video Inc. in a short period before and after the epidemic and data from four consecutive years of annual financial statements. According to the calculation results, the reader can find that during the novel coronavirus epidemic period, Zoom Video Inc.'s operating profit growth rate and net profit growth rate were relatively high and above the industry average value. This showcases that Zoom Video Inc.'s production scale of the enterprise expands rapidly, and it is likely that production sales reputation growth occurs. The data also indicates that the company has increasing enterprise earning, outstanding business performance, and strong market competitiveness. By comparing the short-term data, the author finds that although the company had a high growth rate during the coronavirus outbreak, the second report in 2020 showed a slowdown in growth. Comparing the long-term data, the author finds that the growth rate of net income is consistently higher than the growth rate of operating profit, which shows the profitability of enterprise products is constantly improving. Moreover, it is able to be concluded that Zoom Video Inc. is in the stage of rapid growth with large growth potential.

Therefore, the conclusions are as follows:

1) The short-term growth of Zoom Video Inc. is slowing down and tends to be weak.

2) Zoom Video Inc. has good long-term growth momentum. Long-term investments are worth considering.

TABLE 1. OPEPRFGRRT AND NETPRFGNT OF ZOOM VIDEO COMMUNICATION INC. FROM FOUR QUARTERLY FINANCIAL STATEMENTS AFTER CORONAVIRUS OUTBREAK [7]

\begin{tabular}{|l|l|l|l|l|}
\hline $\begin{array}{l}\text { Zoom Video } \\
\text { Communication } \\
\text { Inc. }\end{array}$ & $\begin{array}{l}\text { Jul. } \\
\mathbf{2 0 1 9}\end{array}$ & $\begin{array}{l}\text { Oct. } \\
\mathbf{2 0 1 9}\end{array}$ & $\begin{array}{l}\text { Jan. } \\
\mathbf{2 0 2 0}\end{array}$ & $\begin{array}{l}\text { Apr. } \\
\mathbf{2 0 2 0}\end{array}$ \\
\hline $\begin{array}{l}\text { Operating } \\
\text { Profit(million) }\end{array}$ & 2.27 & -1.68 & 11 & 23 \\
\hline $\begin{array}{l}\text { Net } \\
\text { Profit(million) }\end{array}$ & 5.54 & 2.21 & 15 & 27 \\
\hline Opeprfgrrt & $/$ & $-174.01 \%$ & $754.76 \%$ & $109.09 \%$ \\
\hline Netprfgnt & $/$ & $-60.11 \%$ & $578.73 \%$ & $80.00 \%$ \\
\hline
\end{tabular}

TABLE 2. OPEPRFGRRT AND NETPRFGNT OF ZOOM VIDEO COMMUNICATION INC. FROM FOUR CONSECUTIVE YEARS OF ANNUAL FINANCIAL STATEMENTS [7]

\begin{tabular}{|l|c|c|l|l|}
\hline $\begin{array}{l}\text { Zoom Video } \\
\text { Communication } \\
\text { Inc. }\end{array}$ & $\mathbf{2 0 1 7}$ & $\mathbf{2 0 1 8}$ & $\mathbf{2 0 1 9}$ & LTM \\
\hline $\begin{array}{l}\text { Operating } \\
\text { Profit(million) }\end{array}$ & $/$ & -4.83 & 6.17 & 35 \\
\hline Net Profit(million) & $/$ & -3.82 & 7.58 & 50 \\
\hline Opeprfgrrt & $/$ & $/$ & $227.74 \%$ & $467.26 \%$ \\
\hline Netprfgnt & $/$ & $/$ & $298.43 \%$ & $559.63 \%$ \\
\hline
\end{tabular}

\subsection{ROIC and G Analysis}

ROIC and increase rate of main business revenue can divide enterprises into four categories:

1) Enterprises with a high growth rate and high ROIC. This type of enterprise has outstanding competitive advantages in the market, maintaining a high return on equity. Also, the industry it belongs to is developing rapidly.

2) Enterprises with a high growth rate and low ROIC. The profitability of this type of enterprise is general, and its capital expenditure is very high. However, the industry it belongs to has good development prospects.

3) Enterprises with a low growth rate and high ROIC. This type of enterprise has good cash flow and prominent competitive advantages in the market, maintaining a high return on equity. The industry it belongs to is developing at a moderate pace. 
4) Enterprises with a low growth rate and low ROIC. The profitability of these companies is poor and the outlook for the industry is bleak.

TABLE 3. ROIC AND INCREASE RATE OF MAIN BUSINESS REVENUE OF SHANGHAI YAOJI TECHNOLOGY CO., LTD FROM FOUR QUARTERLY FINANCIAL STATEMENTS AFTER CORONAVIRUS OUTBREAK[8]

\begin{tabular}{|l|l|l|l|l|l|}
\hline $\begin{array}{l}\text { Shanghai } \\
\text { Yaoji } \\
\text { Technology } \\
\text { Co., Ltd }\end{array}$ & \multicolumn{2}{|l|}{ Date } \\
\cline { 2 - 6 } & $\mathbf{2 0 1 9 Q 1}$ & $\mathbf{2 0 1 9 Q 2}$ & $\mathbf{2 0 1 9 Q 3}$ & $\mathbf{2 0 1 9 Q 4}$ & $\mathbf{2 0 2 0 Q 1}$ \\
\hline $\begin{array}{l}\text { ROIC(\%) } \\
\begin{array}{l}\text { Increase } \\
\text { rate of } \\
\text { main } \\
\text { business } \\
\text { revenue(\%) }\end{array}\end{array}$ & 2.38 & 6.98 & 11.62 & 14.93 & 24.34 \\
\cline { 2 - 6 } & 203.74 & 151.99 & 130.21 & 77.27 & 37 \\
\hline
\end{tabular}

TABLE 4. ROIC AND INCREASE RATE OF MAIN BUSINESS REVENUE OF SHANGHAi YAOJI TECHNOLOGY CO., LTD FROM FOUR CONSECUTIVE YEARS OF ANNUAL FINANCIAL STATEMENTS [9]

\begin{tabular}{|l|l|l|l|l|l|}
\hline \multirow{2}{*}{$\begin{array}{l}\text { Shanghai Yaoji } \\
\text { Technology } \\
\text { Co., Ltd }\end{array}$} & \multicolumn{4}{|l|}{ Date } \\
\cline { 2 - 6 } & $\mathbf{2 0 1 6}$ & $\mathbf{2 0 1 7}$ & $\mathbf{2 0 1 8}$ & $\mathbf{2 0 1 9}$ & LTM \\
\hline $\begin{array}{l}\text { ROIC(\%) } \\
\text { Increase rate of } \\
\text { main business } \\
\text { revenue(\%) }\end{array}$ & 7.4 & 4.7 & 11.1 & 21.8 & 44.1 \\
\cline { 2 - 6 } & -12.2 & -7.1 & 47.8 & 77.3 & 37 \\
\hline
\end{tabular}

In the article, this model analyzes the short-term financial statements of five consecutive quarters and the annual financial statements of five consecutive years of Shanghai Yaoji Technology Co., Ltd before and after the epidemic. Its ROIC and growth rate indicators determine that the company should be defined as a class I or class II enterprise mentioned above. This is the evidence to present that the company has strong operational capacity, especially during the epidemic period, and the industry has a good development prospect. Nevertheless, the explosion of the online entertainment industry might be haphazard. As people have less free time, it is inevitable that the development of game industry will slow down, or even decline. This problem can also be directly reflected by the continuous decrease in the revenue data of main business. Therefore, the results are as follows:

1) Shanghai Yaoji Technology Co., Ltd is a short-term company with prominent competitive advantages and rapid development. Short-term investments during the epidemic are worth considering.

2) The long-term growth of Shanghai Yaoji Technology Co., Ltd. may slow or even decline. Thus, the investment in the long run may not be a beneficial one.

\subsection{MAl and Stock Returns}

Based on the research result of "Influence of Investors' Attention on Stock Returns - Research based on Baidu Index": MAI is in direct proportion to stock returns in the same period, and the returns of stocks with high attention are obviously greater than those with low attention[10], this article will predict the future development of 51Talk through the relationship between MAI and stock returns.

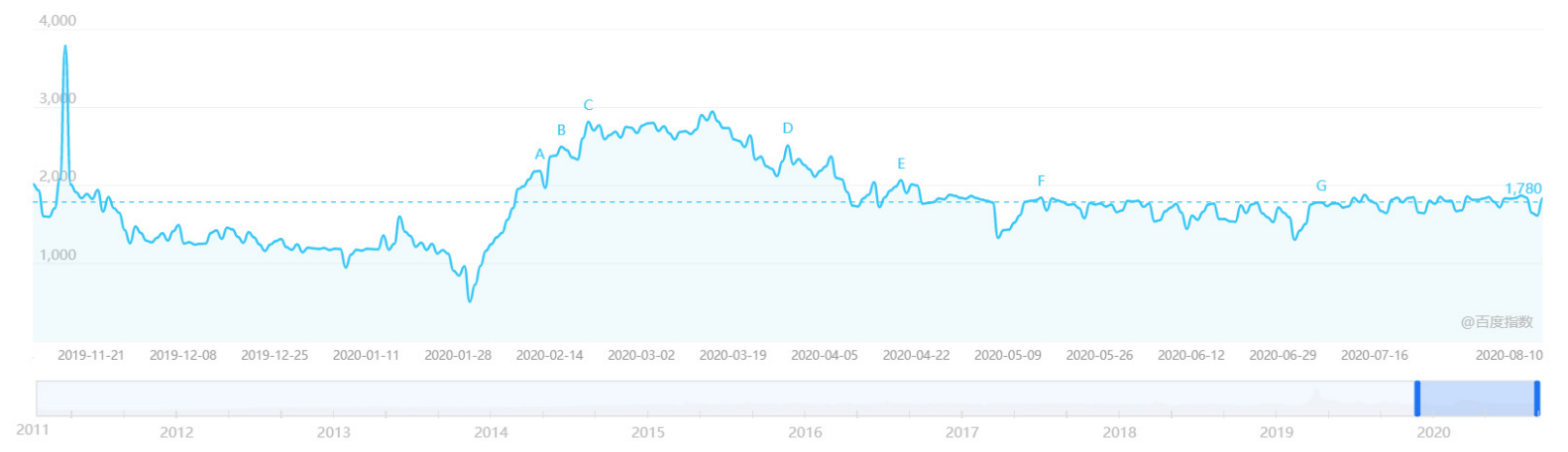

Figure 1. Baidu Index of 51talk from Nov.4th, 2019 to Aug.10th, 2020 [11]

The Baidu index for 51Talk peaked in March and has been trending up on average since May, though it has been falling for the next month. Therefore, baidu index can initially judge 51Talk's stock earnings will be a synchronous upward trend. The author can conclude that there is an upward trend in the value of long-term investments that can be followed continuously.

\section{The Future OF ONLINE INDUSTRIES}

Before the novel coronavirus exploded, the Internet-based online industry had begun to flourish. Under the birth of the epidemic, the Internet industry has seen a spurt of growth. As the public's recognition of online industries increases, their consumption patterns and ideology are gradually changing. Therefore, enterprises in the Internet industry chain begin to gradually improve their business models, expand their business scale, and realize rapid growth. It is undeniable that after the epidemic, due to its advantages of gradual convenience and mature enterprise support, the online industry still has a strong development prospect and contains huge market potential. The online industry may even revolutionize the industrial structure in the future, bringing huge global social and economic impacts. However, the problem is also synchronous. As the situation of epidemic prevention and control gradually improves, much online consumption will move back to the offline. At the same time, as people's leisure time decreases, the development of the online industry is bound to start to decline. With the loss of a large number 
of users, how to maintain the biggest advantage of the online industry and compete with the real industry is an issue that needs to be considered by online enterprises. This article believes that in order to maintain growth, online enterprises should overcome their shortcomings, such as limited business, insufficient profit means, and a large number of competitors, and fully cater to the market to provide customized services for consumers so as to retain consumers.

To sum up, the article holds the opinion that the online industry must have a bright future. However, each enterprise in the online industry has a different future since it is significantly proportional to the strategies that how to maintain its advantages and keep the growth.

\section{CONCLUSION}

Due to the relatively limited scope of the company's business and its immature status, Zoom Video Inc. is not suitable for investment in the short term. However, in the long term, online video conferencing will be the big trend in the future, with great development prospects.

By analyzing the ROIC and increase rate of main business revenue of the enterprise, Shanghai Yaoji Technology Co., Ltd. is in a good state of operation in the short term and relatively competitive in the market, which means it is worthy to make the investment. However, the long-term development of the online game industry will slow down or even come to a standstill due to the resumption of work and schooling.

In the long run, MAI of 51 talk is increasingly growing, so its long-term stock returns should do well and be suitable for long-term investment.

However, the impact of enterprise diversity on the prediction of the future development of online industries is not discussed in this paper. Because the three online industry branches mentioned in this paper are huge, and the companies in the same industrial chain are quite different in terms of line of business, market selection and operation ability, this paper cannot accurately predict the future development of the online industries through analyzing financial data of three typical companies, so as to put forward suggestions for the investment of an industry. Therefore, more evidence should be provided for the above forecast based on more detailed company classification and more comprehensive market analysis data.

\section{ACKNOWLEDGEMENT}

First and foremost, I am very grateful to my professor, teacher assistance, and essay instructor for their careful guidance in helping me accumulate professional knowledge and improve my research and writing skills for the past three months. Further, I would like to thank my parents and group mates for their support and encouragement. Without those people, who gave me academic support or concern in life, I could not have completed this thesis.

\section{REFERENCE}

1. World Health Organization (2020), WHO Director-General's opening remarks at the media briefing on COVID-19 - 11 March 2020. https://www.who.int/zh/dg/speeches/detail/who-dire ctor-general-s-opening-remarks-at-the-media-briefin g-on-covid-19---11-march-2020

2. Andrew Soergel (2020), More Than 33 Million Americans Have Filed for Unemployment During Coronavirus Pandemic.

https://www.usnews.com/news/economy/articles/20 20-05-07/more-than-33-million-americans-have-file d-for-unemployment-during-coronavirus-pandemic

3. Tashanova, Diana and Sekerbay, Ainur and Chen, Danni and Luo, Yuwen and Zhao, Shuyi and Zhang, Qingquan, Investment Opportunities and Strategies in an Era of Coronavirus Pandemic (April 2, 2020). Available at

SSRN: https://ssrn.com/abstract=3567445 or http://d x.doi.org/10.2139/ssrn.3567445

4. Tencent Security (2020), The latest data show that cloud usage by Zoom and Microsoft soared during the coVID-19 crisis.

http://finance.sina.com.cn/stock/relnews/us/2020-0331/doc-iimxyqwa4180565.shtml

5. China Securities Journal (2020), Online entertainment companies are doing well. http://tech.sina.com.cn/roll/2020-03-13/doc-iimxxstf 8584524.shtml?cre $=$ sinapc\&mod $=\mathrm{g}$

6. Chinanews (2020), Non-GAAP Net Profit is 57 million yuan. 51Talk Q1 Achieves Large-scale Continuous Profit . http://www.chinanews.com/business/2020/05-26/91 95528.shtml

7. Zoom Video Communication Inc. $(2017,2018,2019$, 2020), 2017Q4, 2018Q4, 2019Q3, 2019Q4, 2020Q1, 2020Q2 Financial Statements of Zoom Video Communication Inc. https://caibaoshuo.com/companies/ZM/financials\#gu ru_pl_sheet_tab

8. Shanghai Yaoji Technology Co., Ltd (2019,2020), 2019Q1, 2019Q2, 2019Q3, 2019Q4, 2020Q1

Financial Statements of Shanghai Yaoji Technology Co., Ltd https://stock.qianzhan.com/hs/caiwufenxi_002605.sz .html

9. Shanghai Yaoji Technology Co., Ltd $(2016,2017$, 2018, 2019, 2020), 2016Q4, 2017Q4, 2018Q4, 2019Q4, 2020Q1 Financial Statements of Shanghai Yaoji Technology Co., Ltd https:/caibaoshuo.com/companies/002605/financials

10. Zhu Yuan. The Influence of Investor attention on Stock Returns -- A Study based on Baidu Index [J].Hainan Finance, 2014, 000(011):14-17,52.

11. Baidu Index (2019-2020), Baidu Index of 51talk from Nov.4th, 2019 to Aug.10th, 2020. http://index.baidu.com/v2/main/index.html\#/trend/51 talk?words $=51$ talk 